\title{
Exploring cycle crash characteristics in Malaysia
}

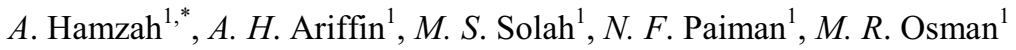 \\ ${ }^{1}$ Vehicle Safety \& Biomechanics Research Centre, Malaysian Institute of Road Safety Research \\ (MIROS), Lot 125-135, Jalan TKS 1, Taman Kajang Sentral, 43000 Selangor, Malaysia.
}

\begin{abstract}
This paper explains the cycle road crash trend, characteristics and injuries in Malaysia. It analyses the in-depth road crash investigation data collected by the Royal Malaysian Police which was made available to MIROS crash database. Fatality data was utilized due to its consistency. Cycle casualties reflected a continual downward pattern for year 2009 to 2014 in which the number of cycle crash involvement reduced by $49 \%$ and fatalities dropped by $42 \%$. Among the prevalent factors of cycle fatalities are $>60$ age group, federal and state roads and straight road sections, rural and small towns, evening peak hours, and mainly involving cars and motorcycles. It is hoped that all these information would spark interests to improve cycle safety in Malaysia.
\end{abstract}

\section{Introduction}

Bicycling or cycling in general, has been showing a resurgence in popularity on Malaysian roads recently. Cycling for sport and leisure are prevalently more visible than for commuting for work and utilities, though cycling is practically favorable for health and also the environment $[1,2]$. Factors such as hot and humid weather were among the concerns for the low propensity to cycle. Connectivity, accessibility and traffic safety also influenced the cycling motivation [3]. With respect to road traffic injuries, cycling fatalities is ranked fourth in statistical records after motorcycle, car and pedestrian [4]. However, number of active cycles and cyclists are very challenging to be estimated due to fairly loose cycle registration policy. The requirement to register falls under the purview of local government authorities [5]. Nevertheless, observational studies of cycle use were able to provide preliminary indications of the users' population, though in fragments [6,7]. Additionally, cycle safety research seems yet to be a subject of high interest to the research community in Malaysia and it is hoped that this introductory information would spur the motives.

This report attempts to describe cyclists' road traffic injuries risks relative to fatality records and analyse the cycle crash characteristics and at the same provide a basis for future cycle-centric research.

\footnotetext{
* Corresponding author: azhar@miros.gov.my
} 


\section{Methodology}

Road traffic casualties' data from the year 2009 to 2014 was acquired from the publication of Royal Malaysian Police and was used to reflect the overall injury trend [11]. For indepth analyses, data for 2009 to 2013 which were documented in MIROS database system were utilized due to information extensiveness and accessibility [12]. Fatality records for all five years were aggregated together for ease of analyses and to provide clear visibility. The fatality data were considered in the analyses due to its high reliability and accuracy $[8,9]$. The severe and slight injuries records were disregarded due to concerns of incomplete and possibly massive underreporting, especially for cycle crashes $[9,10]$. This paper forms part of preliminary study on cycle safety in Malaysia.

It is to be noted that quite a substantial amount of unknown data was observable especially in Figure 2, 5 and 6 which concern cycle fatalities over age groups, time of day and also collision type, respectively. Such issue could be possibly attributed to incomplete information and data entry inaccuracies during processing, which should be looked into to improve data reliability.

\section{Results}

\subsection{Cycle casualties, 2009-2014}

Cycle injuries in Malaysia has been showing a consistent reduction for the last few years, as shown in Figure 1. Though the serious and minor injuries accident data were doubted by some studies, the trend reflected a similar downward pattern to fatal injuries. From 215 fatalities in 2009 , the absolute fatal number has dropped to 124 in 2014 , indicating a $42 \%$ reduction in the 6-year span and is shown by the trend line.

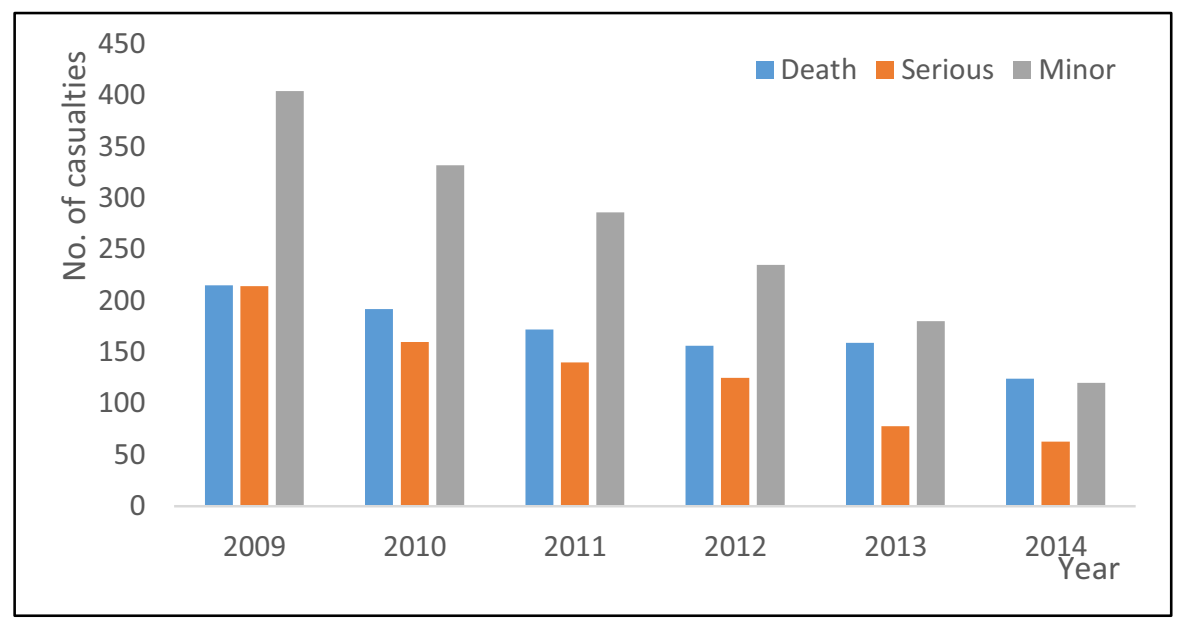

Fig. 1. Cycle casualties in road traffic [12].

Correspondingly, the number of cycles involved in road crashes has also reflected a continual downward pattern throughout the six years, with year 2013 recorded a considerable 31\% drop. Comparing year 2009 to 2014, the cycle involvement in crashes has dropped significantly by $49 \%$. 
Table 1. Number of cycles involved in crashes [12].

\begin{tabular}{|c|c|c|}
\hline Year & No. of cycles & Year to year reduction, \% \\
\hline 2009 & 2486 & - \\
\hline 2010 & 2178 & 12 \\
\hline 2011 & 2033 & 7 \\
\hline 2012 & 2000 & 2 \\
\hline 2013 & 1370 & 31 \\
\hline 2014 & 1275 & 7 \\
\hline
\end{tabular}

\subsection{Cycle fatalities by age group}

The dominant age group was $>60$ year-old which represents about $26 \%$ (234 fatalities with average of 46 per year) of the total cycle fatalities (Figure 2) and displayed a substantial surge in comparison to other age groups. Fatalities among other age groups were scattered between 20 to 49 fatalities, excluding the age group of 1 to 5 year-old.

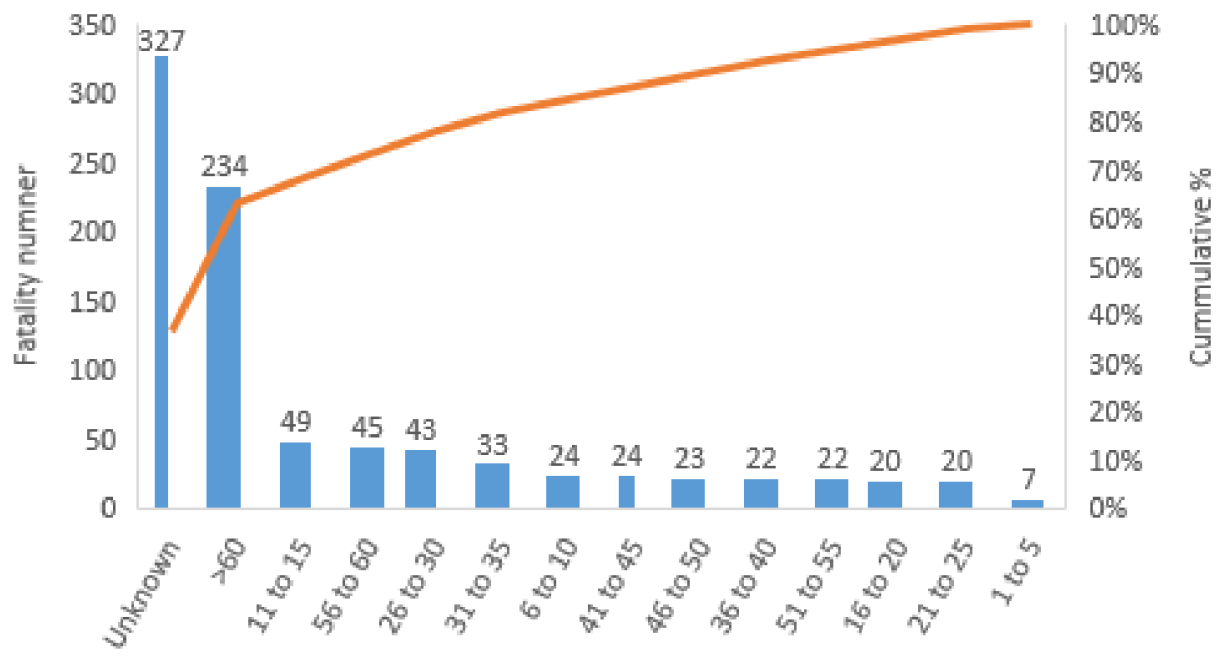

Age group

Fig. 2. Cycle fatalities by age group [12].

\subsection{Cycle fatalities by road category and locality}

In terms of road type, more than half of cycle fatalities occurred in the federal (28\%) and state $(25 \%)$ roads, as shown in Figure 3 (1). About $19 \%$ of fatalities occurred in municipal roads. For locality, rural (31\%) and small town (14\%) areas dominated the fatality record. Fatal cases in town and city were rather comparatively low ( $9 \%$ and $3 \%$, respectively).

\subsection{Cycle fatalities by road geometry}

Straight road section was the most dangerous for cyclists (63\%) and was followed by $\mathrm{T} / \mathrm{Y}$ junctions (6.9\%) and cross junction (4.5) (Figure 4). Curve sections and roundabout 
accounted for $3.7 \%$ and $1.7 \%$, respectively. Cycle fatalities at staggered junction was low at $0.2 \%$.
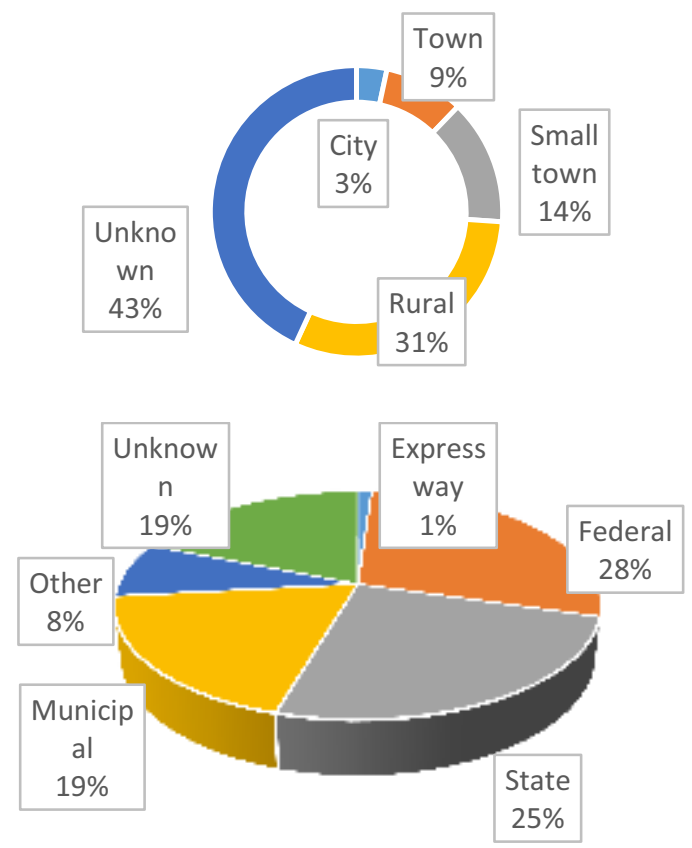

Fig. 3. Cycle fatalities by road category (1) \& locality (r) [12].

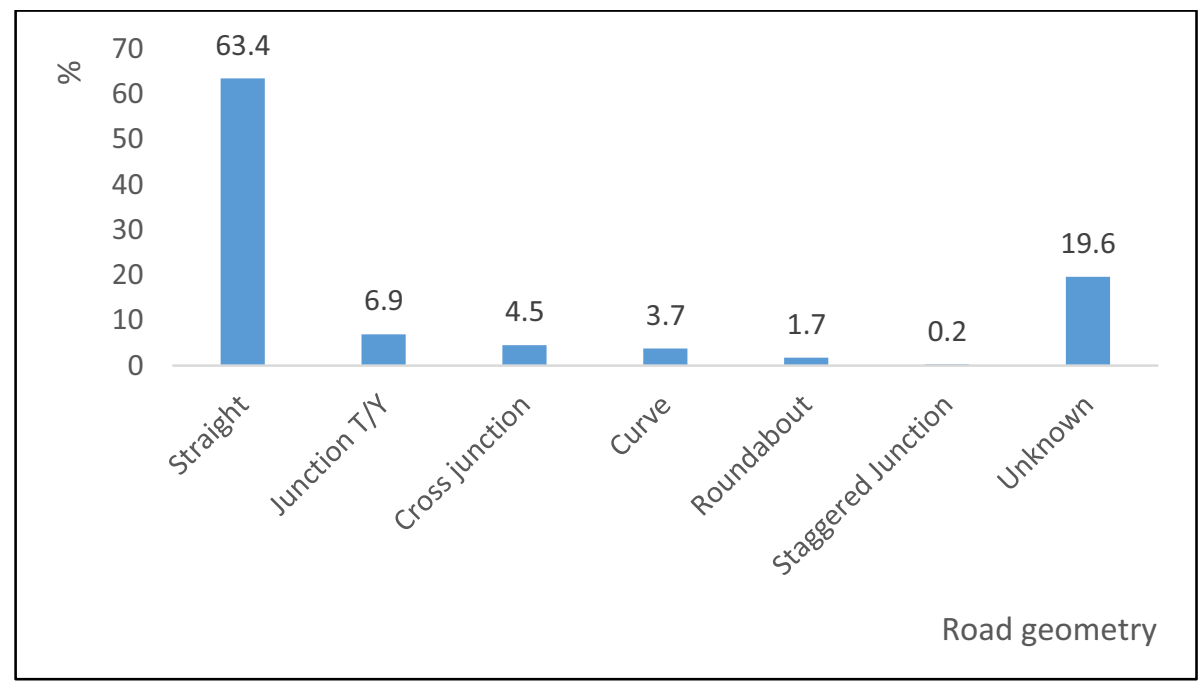

Fig. 4. Cycle fatalities by road geometry [12].

\subsection{Cycle fatalities by time of day}

More than 200 fatalities occurred around the time of 1801-2200 hours and were closely followed by 0601-1000 hours ( $>160$ fatalities), as shown in Figure 5. These time intervals 
coincide with the common peak commuting time. Moreover, cycle fatalities spread in all time intervals including midnight and early wee hours which was a startling fact.

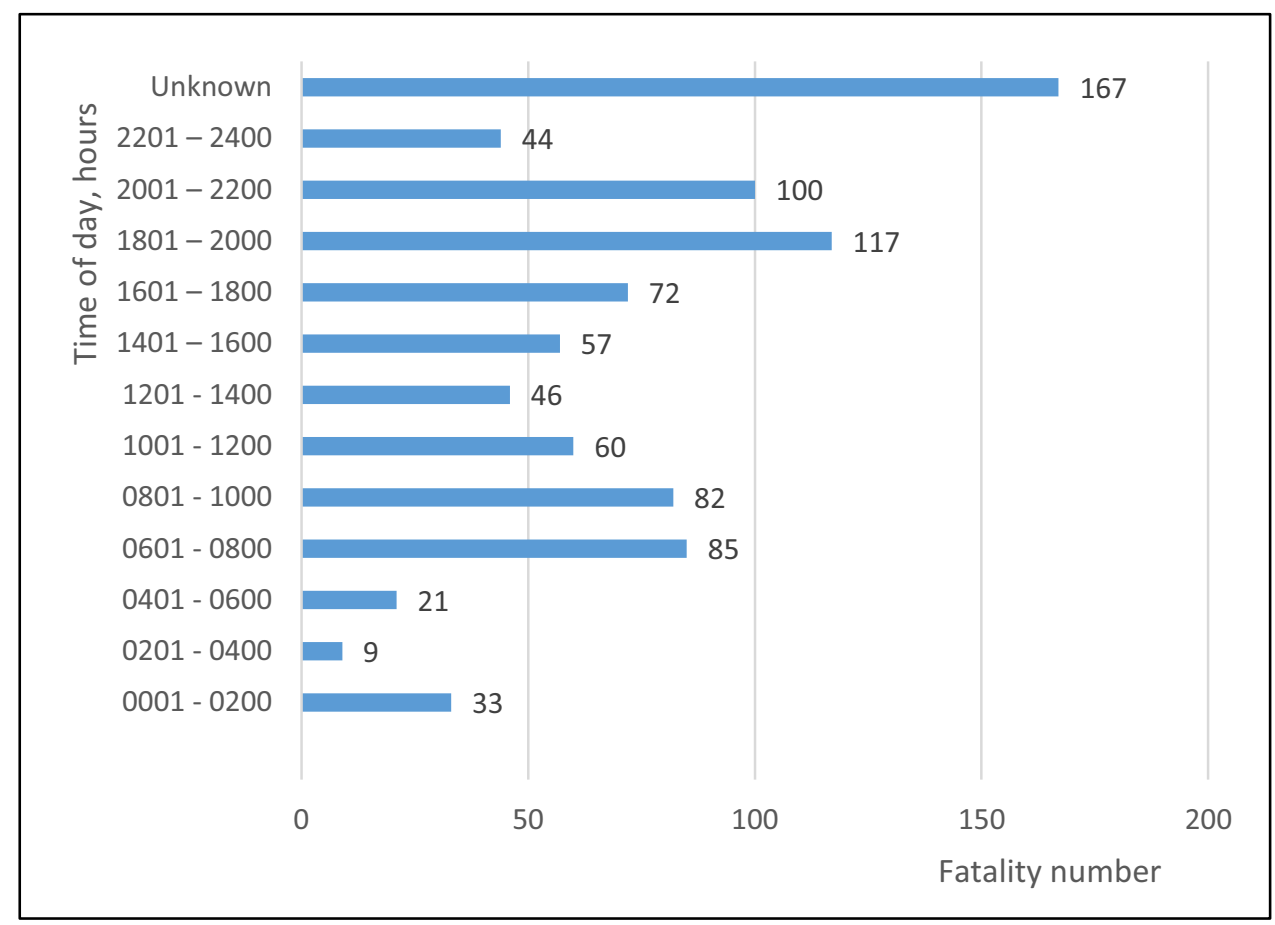

Fig. 5. Cycle fatalities by time of day [12].

\subsection{Cycle fatalities by collision type}

Based on Figure 6, angular/side collision was the most prevalent collision type (17.6\%) with rear end $(11.2 \%)$ and side swipe $(10.3 \%)$ collisions were the next serious types. Other collision types include 90-degree (6.6\%), head-on (5.7\%) and out-of-control (1.1\%). There were a few collision types which accounted less than $1 \%$ each, namely involving pedestrian, object on ground and off-road, squeezed and overturned.

\subsection{Cycle fatalities by vehicle type}

Car - cycle and motorcycle-cycle were the most common collisions (35.6\% and $21.6 \%$ respectively) (Figure 7). There were extensive involvements of other mode of transports, ranging from few types of buses and lorries.

\subsection{Cycle lane and facilities}

In general, cycle lanes and cycle facilities are still lacking in cities and towns except in certain public parks and recreational areas. A brief survey of cycle facilities was conducted in few selected cities and areas, namely Putrajaya, Petaling Jaya and Pulau Pinang. The main aims were to have an overview of cycle lanes and cycle-related policies consideration in town planning and development. In short, cycle lanes and cycle-related facilities are indeed given considerable attention in existing town expansion plan and in new 
development projects where sustainable development and green initiative has been set as the key elements for growth. A number of cycle lanes and facilities have been constructed to encourage safe cycling and proper point to point connectivity (Figure 8). Nevertheless, a lot more are needed.

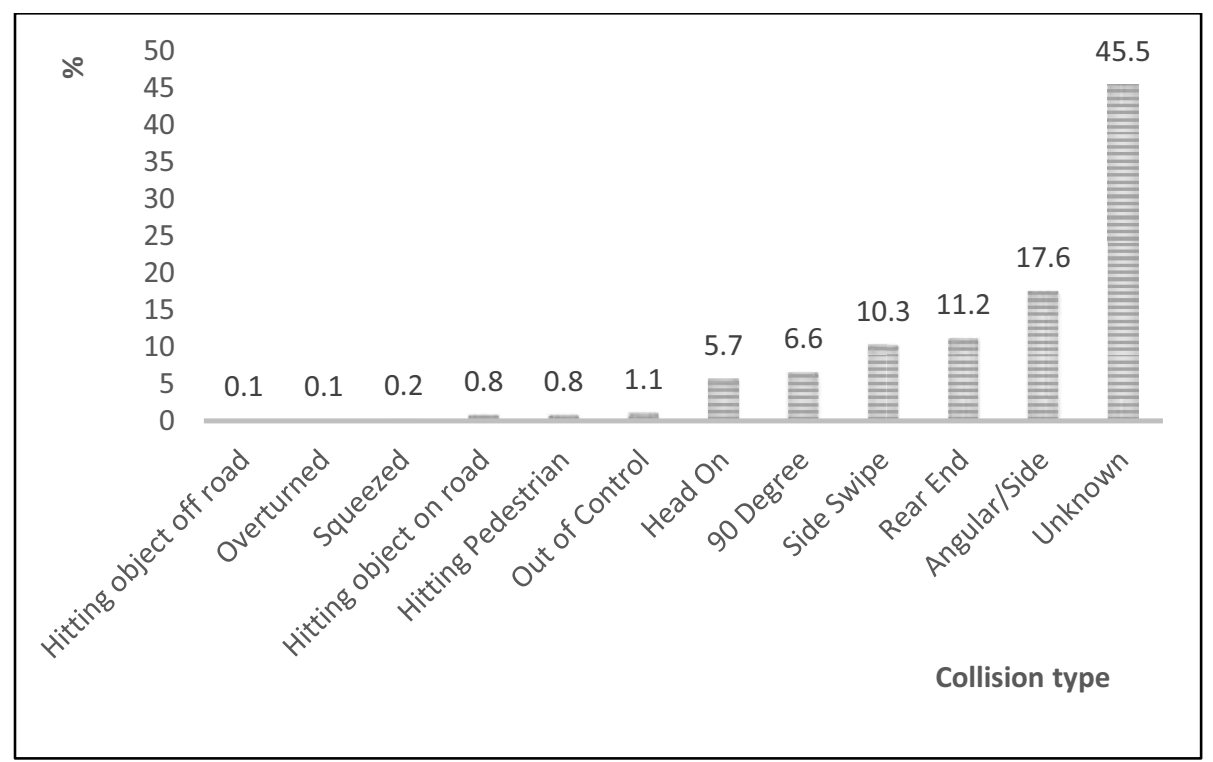

Fig. 6. Cycle fatalities by collision type [12].

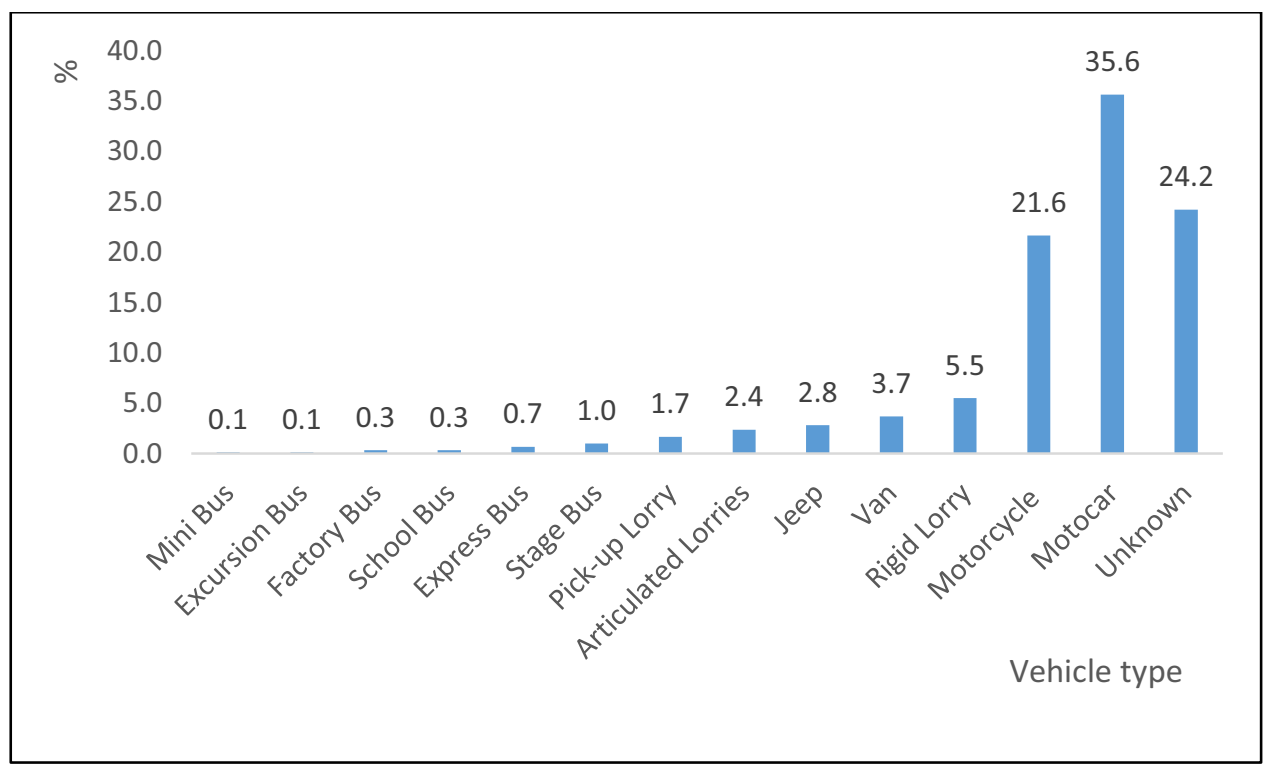

Fig. 7. Cycle fatalities by vehicle involvement [12]. 


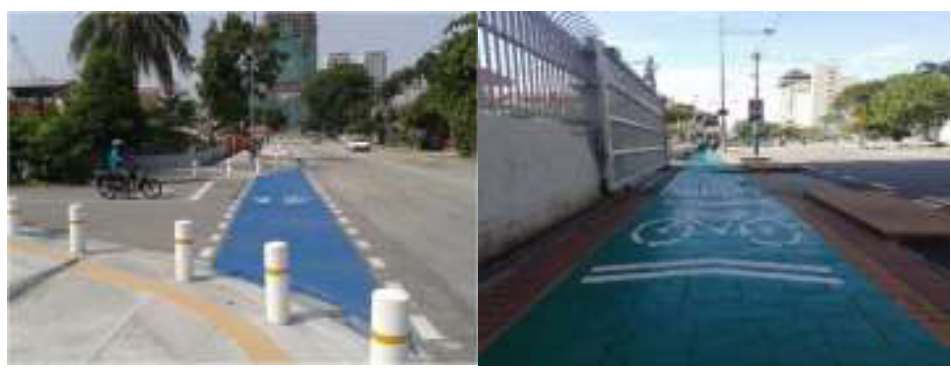

Fig. 8. Cycle lanes in Petaling Jaya (1) and Pulau Pinang (r).

\section{Discussion}

Overall cycle fatalities reflected a downward trend from the year 2009 to 2014 and this favorable reduction was mainly originated from the age groups listed in Table 2. Main improvements were from the age group of 11 to $15(57 \%)$ and 21 to 25 year-old $(50 \%)$ while other age group displayed encouraging improvements. In term of absolute number, the unknown group was the biggest contributor to the decrease. 11 to 15 age group are school-going children however it could not be established whether the cases occurred during commuting to or from school.

Table 2. Reduction in cycle fatalities [12].

\begin{tabular}{|c|c|c|c|c|}
\hline Age group, years & Mean & $\mathbf{2 0 0 9}$ & $\mathbf{2 0 1 3}$ & \% Reduction \\
\hline 11 to 15 & 9.8 & 14 & 6 & 57 \\
\hline 21 to 25 & 4 & 4 & 2 & 50 \\
\hline 26 to 30 & 8.6 & 10 & 6 & 40 \\
\hline 31 to 35 & 6.6 & 7 & 4 & 43 \\
\hline 36 to 40 & 4.4 & 5 & 4 & 20 \\
\hline Unknown & 65.6 & 69 & 35 & 49 \\
\hline
\end{tabular}

Cyclists with age group of $>60$ year-old were the most dominant $(26 \%)$ in cycle fatalities with an average of 46 numbers for the year 2009 to 2013. It is a known fact that elderly cyclists have the highest crash and injury risks among vulnerable road users and their overrepresentation in cycle deaths could go as high as 70\% [13]. Cyclists in this age group involved in crashes most probably cycle for utility or leisure purposes, possibly at non-peak hours. A big portion (72\%) of cycle fatalities took place in federal, state and municipal roads and were more prominent in small towns and rural areas (45\%). With regards to road geometry, big majority of cycle deaths happened at straight road sections $(63 \%)$. Correspondingly, straight section was also reported as the most hazardous in motorcycle crashes [4].

The time of day could be further classified into day, night and others with regards to the availability of natural light, though the cut-off time is arguable (Table 3). About $35 \%$ of fatal cycle crashes occurred during daylight. Cases at dusk and dawn (23\%) were similar to cases at night although the time intervals at night were relatively more than double. A surprising fact is that there was a substantial fatality at night $(23 \%)$, possibly indicating the presence of considerable number of active cyclists on roads. Cycle naturally has low conspicuity on roads due to its narrow size and low light environment may exacerbate it crash risk [14]. 
Table 3. Cycle fatalities according time of day [12].

\begin{tabular}{|c|c|c|c|}
\hline Time of day & Time interval & Fatalities & $\mathbf{\%}$ \\
\hline Day & $0801-1800$ & 317 & 35 \\
\hline Dusk & $1801-2000$ & 117 & 13 \\
\hline Night & $2001-0600$ & 207 & 23 \\
\hline Dawn & $0601-0800$ & 85 & 10 \\
\hline Unknown & - & 167 & 19 \\
\hline
\end{tabular}

Angular/side collision was the most prominent collision type (17.6\%) and considering fatal injuries and the common cycle speed, the opposing vehicles were presumably the most likely striker. The most two common opponents for cycle crash were passenger cars $(35 \%)$ and motorcycles $(22 \%)$ and could be explained by their high registration in the country. One way to improve the situation is by segregating cycles from other transport mode by creating designated cycle lanes [15]. The initiative to create cycle lanes in existing road networks is strongly encouraged to promote safe cycling.

\section{Conclusions}

Cycle involvement in road crashes in Malaysia has been showing a considerable decrease for the past few years till 2014. This positive improvement is reflected by lower cycle involvement in road crashes which consequently lead to fewer cycle deaths and injuries. However, the current records showed that the elderly group of $>60$ years old was overrepresented with an average of 46 deaths occurred annually. Most cycle deaths happened in straight road sections, at the state and federal road class, and in rural and small towns. By time of day, peak commuting hours in early morning (0600-1000 hours) and late afternoon (1800-2200 hours) were the commonest period for fatal crashes. The most fatal crash configuration was angular/side impacts involving predominantly passenger cars (motorcar) and motorcycles. Having all these information, it is hoped that more researches, effort and initiatives would be put in place to further improve cycle safety in the country.

The authors would like to extend their greatest appreciation to MIROS for providing the grant, to MIROS Crash Data \& Exposure Analysis Unit for the assistance in providing traffic crash details. Lastly, greatest gratitude to Royal Malaysian Police for sharing their precious accident data.

\section{References}

1. http://malaysiacycling.blogspot.my, accessed May 21, (2016).

2. A. S. I. Almselati, R. Rahmat, O. Jaafar O, "An overview of urban transport in Malaysia," Social Sci. 6(1):24-33, (2011).

3. B. Afsar, Y. M. Golriz Nikjooy, "The consequences of the physical-environmental factors on encouraging pedestrian and cycling activities in UPM Campus," Int. J. Sci. \& Eng. Research, v6 (1), (2015).

4. M. M. Abdul Manan, A. Várhelyi. "Motorcycle fatalities in Malaysia,". IATSS Research. Jul; 36(1):30-9, (2012).

5. Act 171, Local Government Act, 1976, Laws of Malaysia.

6. M. R. M. Yazid, R. Ismail, R. Rahmat, M. Nazri, "City residence prepare towards implementation local lane of non-motorized". Res. J. App. Sci., Eng. and Tech., Selangor, Malaysia. 2012; 4(5):481-485, (2012).

7. S. A. A. Dawood, O. K. Rahmat R. A, "Factors that affect cycling transportation mode 
for postgraduate students at Universiti Kebangsaan Malaysia by logit method. Jurnal Kejuruteraan. 27:1-7, (2015).

8. N. Haworth, "How valid are motorcycle safety data?" The Road Safety Research, Policing and Education Conference, Sydney, Australia, (2003).

9. D. L. Rosman, M. W. Knuiman, "A comparison of hospital and police road injury data". Accident Analysis \& Prevention. 26(2):215-222, (1994).

10. R. Elvik, A. Mysen, "Incomplete accident reporting: meta-analysis of studies made in 13 countries". Transportation Research Record: Journal of the Transportation Research Board. Jan 1(1665):133-40, (1999).

11. Laporan Perangkaan Kemalangan Jalan Raya Malaysia, Polis Diraja Malaysia, 20092014.

12. MRoads cycle crash report, Malaysian Institute of Road Safety Research, (2016).

13. J. Oxley, B. Corben, B. Fildes, M. O'Hare, T. Rothengatter. "Older vulnerable road users- measures to reduce crash and injury risk". Monash University Accident Research Centre Reports. (218):162, (2004).

14. S. J. Thornley, A. Woodward, J. D. Langley, S. N. Ameratunga, A. Rodgers. "Conspicuity and bicycle crashes: preliminary findings of the Taupo Bicycle Study". . Injury Prevention.14(1):11-8, (2008).

15. J. Parkin, C. Meyers. "The effect of cycle lanes on the proximity between motor traffic and cycle traffic". Accident Analysis \& Prevention. 42(1): 159-65, (2010). 